\title{
Concepciones de futuros profesores de Ciencias de la Educación sobre dimensiones relevantes de la actuación docente
}

\section{Conceptions of future teachers of science of education on relevant dimensions of the teaching performance}

\author{
Lic. Fernando Agustín S. Flores ${ }^{1}$
}

Fecha de recepción: 03/08/2012

Fecha de aceptación y versión final: 18/11/2012

\begin{abstract}
Resumen: Se informan resultados de una investigación, que tuvo como objetivo caracterizar en sus rasgos más salientes las modelizaciones de estudiantes del profesorado en Ciencias de la Educación sobre la actuación docente, para su puesta en relación con las tradiciones de la formación de profesores. Específicamente, el análisis pretende dilucidar las concepciones que poseen estos estudiantes sobre las fuentes de aprendizaje docente, la buena enseñanza y el buen aprendizaje; e identificar la presencia en tales concepciones de núcleos definitorios de tradiciones y tendencias de la formación docente. El estudio se llevó a cabo en la Facultad de Humanidades de la Universidad Nacional del Nordeste. La muestra estuvo conformada por veintidós estudiantes próximos a finalizar su trayecto formativo inicial. Se aplicaron dos instrumentos para la obtención de información, un cuestionario semi-estructurado y los grupos focales. Los resultados obtenidos mediante la implementación del primer procedimiento muestran que los estudiantes son conocedores de los diferentes modelos teóricos de docencia, reconocen claramente entre un conjunto de dimensiones y opciones que informan de la actuación docente y que aluden a distintos enfoques, aquellas correspondientes a perspectivas actuales tales como el modelo práctico reflexivo y el critico emancipatorio. Por su parte, la puesta en debate e interacción que implicó el segundo procedimiento, ofrece un nuevo significado y contorno a sus concepciones. En efecto, se percibe cierta dilución y de algún modo volatilización de la correspondencia configurada, nos sitúa en una conjunción más profunda que podemos caracterizar como concepciones constituidas por una mixtura de perspectivas de diferentes orígenes.
\end{abstract}

Palabras clave: Fuentes de aprendizaje, enseñanza y aprendizaje, estudiantes universitarios.

Abstract: The results of an investigation has been reported, the objective was to characterize its salient features in the modelling of students in Science Teacher Education on teaching performance, to put it in relation to the traditions of teacher training. Specifically, the analysis aims to clarify the concepts that have these students on sources of teacher learning, good teaching and good learning and identify the presence of nuclei in such conceptions defining traditions and trends of teacher training. The study was conducted at the Faculty of Humanities at Northeastern University. The sample consisted of twenty-two students near the end of their initial training course. Two instruments were applied to obtain information, a semistructured questionnaire and focus groups. The results obtained by implementing the first method show that students are aware of the different theoretical models of teaching, clearly recognized among a set of dimensions and options report teaching performance and relating to different approaches, current prospects for those such as reflective practitioner model and the critical emancipatory. Meanwhile, the discussion commissioning and interaction that the second procedure involved, give a new meaning and shape to their ideas. Indeed, there is some perceived dilution and volatilization somehow configured correspondence, puts us in a conjunction deepest which can be characterized as conceptions formed by a mixture of perspectives from different backgrounds.

Key words: Sources of learning, teaching and learning, university students.

\footnotetext{
${ }^{1}$ Facultad de Humanidades - UNNE - correo electrónico: fas_flores@yahoo.com.ar
} 


\section{Introducción}

En este artículo se exponen resultados seleccionados de una investigación ${ }^{2}$, cuyo propósito fue caracterizar - en sus rasgos más salientes - las modelizaciones de futuros profesores en Ciencias de la Educación sobre la actuación docente, para examinarlas en la relación que mantienen con los modelos y tradiciones en la formación docente. En esta oportunidad, la propuesta es analizar las concepciones de estos estudiantes en dimensiones relevantes de la actuación docente, tales como las fuentes de aprendizaje docente, y las características que prevalecen al considerar la buena enseñanza y el buen aprendizaje. Asimismo, el análisis pretende ubicar estas concepciones en el terreno de las tradiciones y tendencias vigentes de la formación docente.

Este trabajo se sitúa en la línea de investigación del pensamiento pedagógico de docentes y estudiantes. En un marco predominantemente psicológico, surgen diversos estudios que enfocan los procesos de pensamiento del docente en formación y en ejercicio, hacen hincapié en sus concepciones, creencias personales, representaciones y teoría implícitas. Para Rodrigo, Rodríguez y Marrero (1993), este tipo de estudio abre la posibilidad de penetrar en la red ideológica de teorías y creencias que condicionan el modo como el docente da sentido a su mundo en general y a su práctica pedagógica en particular. En sus orígenes esta perspectiva mostró interés en los procesos de pensamiento del profesor implicados en la planificación didáctica y en la interacción áulica. Entre los representantes más destacados se pueden citar a Yinger (1986), Shavelson y Stern (1989), Shulman (1989), y Clark y Peterson, (1986).

En la actualidad existen numerosos trabajos que comparten el presupuesto de que la práctica docente, en los distintos ámbitos del sistema educativo, está mediada por el sistema personal de concepciones y creencias, que a su vez es la fuente de sentido donde se apoya la acción del profesor (Pozo, 2006). Estas producciones se diversifican en disciplinas específicas. Por ejemplo, Córdova (2006), indaga el pensamiento pedagógico de los estudiantes de educación. A su vez, Dodera, Burroni, Lázaro y Piacentini (2008) analizan las concepciones y creencias de profesores sobre enseñanza y aprendizaje de la matemática. En este sentido, Figueroa y Páez (2009) citan otras investigaciones, y llegan a la conclusión de que el pensamiento del profesor es una línea de investigación compleja, preponderantemente subjetiva, singular y constituida por múltiples variables, que requiere prácticas investigativas reflexivas.

Particularmente, el presente artículo se orienta al examen de las concepciones que emergen de las valoraciones y proyección que realizan estudiantes del último año del profesorado sobre las fuentes de aprendizaje docente, la buena enseñanza y el buen aprendizaje. Desde este punto de vista, se adopta la definición de concepciones expuesta por Ponte (1994), que las entiende como marcos organizadores implícitos de conceptos, de naturaleza esencialmente cognitiva y que condicionan la forma en que se afrontan las tareas (citado en Dodera, et. al. op. cit.). Asimismo, Juan Ignacio Pozo en distintos estudios (2001, 2003, 2006 y 2009), expone una serie de características constitutivas de las concepciones. Son productos de aprendizajes informales, es decir se aprende a través de la acción propia o vicaria. Sin embargo, aún no habiendo sido elaborados concientemente por cada sujeto, actúan como supuestos obvios sin los cuales carecería de sentido lo que se hace. Son elaboraciones personales, cuyo

\footnotetext{
${ }^{2}$ Tesis de Licenciatura en Ciencias de la Educación. Denominación: Apropiación de modelos de docencia en estudiantes futuros profesores. Presentada y defendida en el año 2009. Directora: Corral, Nilda. Facultad de Humanidades de la Universidad Nacional del Nordeste.
} 
formato y contenido surgen de la participación en determinados grupos sociales que comparten actividades comunales, se activan durante la inserción en las instituciones y sus culturas. Finalmente, son de naturaleza encarnada, difíciles de controlar conscientemente y, por tanto, resistentes al cambio.

Señas de identidad cognitiva, las concepciones de los futuros profesores también encuentran expresión en lo que más valoran de las fuentes de aprendizaje docente, y en las características que imaginan poseen la buena enseñanza y el buen aprendizaje. Específicamente, se propone entonces desentrañar la presencia en estas concepciones intuitivas y encarnadas, de núcleos definitorios de modelos de docencia transmitidos a través de la formación y en la práctica pedagógica. Algunos de estos modelos han sido conceptualizados por Davini (1995) como tradiciones, que surgieron en un determinado momento histórico y se mantienen a través del tiempo, pues están institucionalizados e incorporados a las prácticas pedagógicas y a la conciencia de los sujetos; además, se incluyen otros modelos con características que no se ajustan cabalmente a la idea de tradición, estos modelos son concebidos como enfoques o tendencias que poseen circulación más difusa en el profesorado, su presencia más fuerte se liga al discurso y al imaginario de los docentes y aparece más débil respecto al grado de incidencia en la estructuración de planes y experiencias concretos de formación del profesorado.

Los distintos modelos, tal como lo expresa Davini (op. cit.), hegemónicos en un determinado momento histórico, no configuran instancias compactas o puras, dado que se dan en su interior contradicciones y divergencias; y ellas mismas coexisten, influyéndose recíprocamente.

Se distinguen cinco modelos de docencia, cuyas conceptualizaciones básicas permiten comprender las funciones y exigencias que se le asignan al docente en cada uno de ellos. A continuación brevemente se reseña cada uno de estos modelos, los cuales establecen sus propias orientaciones y denominaciones respecto a la formación docente. Estos modelos poseen señales inequívocas que favorecen la diferenciación entre unos y otros.

La reconstrucción conceptual de estos modelos se nutre de los aportes de diversos autores (Pérez Gómez, 1992; Davini, 1995; Diker y Terigí, 1997; Vaillant, 2005; Angulo Calzadilla, 2012). Además, se incluyen secundariamente los aportes de otros autores con el fin de esclarecer algún aspecto particular que se aborda, aunque no necesariamente en ellos se encuentra una clasificación de modelos de docencia similar. Las dimensiones que se incluyen en los modelos son: el rol del profesor y la imagen asociada al mismo; las fuentes de aprendizaje docente; las características de la buena enseñanza y el buen aprendizaje; la relación entre la teoría y la práctica; y la evaluación de los aprendizajes.

\section{Modelo academicista.}

La formación del profesor se vincula exclusivamente con el dominio de la disciplina que ha de enseñar, lo esencial es conocer solidamente la asignatura. En tal sentido, aprender a ser profesor tiene que ver, ante todo, con la incorporación formal de los significados abstractos enmarcados en las disciplinas. Del mismo modo, la enseñanza es entendida como un proceso de transmisión de conocimientos. Señalan Porlan y Rivero (1998), que la transmisión de contenidos se lleva adelante según el criterio de la estructura lógica de las disciplinas, sin referencia al contexto y a las necesidades formativas de los alumnos. En síntesis, la competencia del profesor reside en la adquisición de conocimientos disciplinares y en la capacidad para explicar con claridad 
y orden dichos contenidos. Mientras que el alumno deberá demostrar lo aprendido fundamentalmente a partir de la reproducción literal de los conocimientos impartidos básicamente mediante la transmisión verbal de conceptos por parte del docente, es más importante que él sea capaz de repetir lo dicho por el docente que su capacidad de comprender y apropiarse del conocimiento. En efecto, la evaluación en este modelo tiende hacia la memorización y repetición mecánica de conceptos. La evaluación en el sentido aludido no tiene en cuenta los significados y conocimientos previos que los alumnos y alumnas pudieran poseer. En esta forma de evaluar no se contempla el proceso de aprendizaje de los estudiantes, sino que se concentra en corroborar la acumulación de conocimientos lograda en un cierto lapso de tiempo, esto es, atiende exclusivamente al resultado, el cual es objeto de una nota.

\section{Modelo técnico - eficientista.}

La actividad docente se concibe como eminentemente técnica, la labor del profesor consiste en bajar a la práctica, de manera simplificada, el currículo prescrito por expertos externos en torno a objetivos de conducta y medición de rendimientos. Se aspira a tecnificar la enseñanza sobre la base de un tipo de racionalidad denominada instrumental, con economía de esfuerzos y eficiencia en el proceso y los productos. En consecuencia, el enseñante es reconocido como un profesional en función del dominio técnico que demuestre en la solución de problemas. Al decir de Contreras (1996), el docente actúa aplicando soluciones disponibles a problemas ya formulados. Para Gimeno (1983) este modelo encaja con el Paradigma técnico y se manifiesta en la adquisición de competencias entre las que se cuentan: la programación por objetivos y la elaboración y aplicación de instrumentos de evaluación para medir el alcance de los objetivos propuestos. Siguiendo el análisis propuesto por Diker y Terigi (op. cit.), a los problemas de la práctica que enfrenta el profesorado el enfoque tecnocrático ofreció una alternativa racionalizadora, la secuencia técnica de la programación se ofrecía como un proceso de aplicación del conocimiento proposicional a la acción. Orientar el trabajo en la clase hacia el cumplimiento de objetivos precisos y traducirlos a comportamientos observables en donde se pueda constatar el cumplimiento de los mismos, encontró soporte teórico desde las aportaciones de la psicología conductista. En cuanto a la evaluación, se incorporó procesos de medición y cuantificación, la comprobación de los resultados de aprendizaje se realizaba en función de objetivos precisos, se aplicaba una taxonomización de los objetivos para comprobar el aprendizaje de forma clara y exacta.

\section{Modelo práctico, en sus dos orientaciones.}

La primera variante, de corte espontaneista, sostiene que aprender la profesión docente requiere un proceso de inmersión en la cultura de la escuela mediante el cual el futuro profesor se socializa dentro de la institución, aceptando la cultura profesional heredada y los roles profesionales correspondientes. Se aprende a enseñar enseñando, sin necesidad de un diseño específico o de una ayuda externa. Respecto a la enseñanza, son los intereses del alumno, sus motivaciones, sus relaciones con el medio los que actúan como ejes estructurantes de la clase escolar. Rodríguez (1995: 20) denomina este modelo como concepción tradicional-oficio y explica que entre los aspectos negativos dentro del currículo de Formación Inicial se encuentra la separación y fragmentación entre la teoría y la práctica. En palabras del autor: 
"Tras un período de observación se enfrentaba al aprendiz con la realidad escolar de forma que, imitando el modelo y por un proceso de ensayo y error alcanzaría el dominio de las técnicas de enseñanza."

La segunda variante, de orientación reflexiva, el profesor se comporta como un práctico reflexivo, ante los complejos, inciertos y cambiantes problemas de la práctica educativa. El profesional docente se forma en tanto somete su actividad a la investigación o reflexión sistemática y racional, poniendo a prueba sus estrategias de trabajo. Este movimiento desdibuja la diferencia entre los investigadores de la educación y la docencia; rompe la división entre los que estudian la educación, los que deciden sobre ella y los que la hacen o realizan. El docente y su práctica se constituyen en objeto de estudio del propio docente, como vía para mejorar su práctica y por ende, formarse profesionalmente. Un autor que se ubica en este modelo es Schön (1992), quien analiza la epistemología de la práctica implícita que ocurre en las actividades de enseñanza, las cuales caracteriza como inciertas, inestables, singulares en las que encuentra conflictos de valor. A su vez, esa epistemología es interpretada como reflexión en la acción, es decir, el conocimiento no precede la acción, sino que está en la acción.

\section{Modelo crítico.}

Se reconoce la dimensión política de los actos educativos desde un propósito emancipatorio y se propone un proceso de formación que apunta a la constitución de profesores como intelectuales transformativos. En efecto, el lugar del docente se entiende desde un doble compromiso: la transmisión de un saber crítico y la transformación social. Entre los autores más reconocidos se ubican Apple (1986), Carr y Kemmis (1988), Giroux, H. (1990), Freire, P. (1996). Se plantea desde este enfoque la necesidad de reexaminar las relaciones existentes entre escuelas y sociedad dominante, se preguntan ¿cómo el currículo reproduce las relaciones económicas y sociales? y ¿cómo las relaciones cotidianas del aula generan valores culturales y relaciones sociales? Por su parte, la característica central de las prácticas evaluativas que promueven la perspectiva crítica - emancipatoria es facilitar y promover el cambio, no se concibe a la evaluación como una mera actividad cognoscitiva y valorativa. El cambio que se proclama no es aparente ni circunstancial, sino la transformación real mediante la modificación de concepciones, creencias y modos de interpretar de los actores que participan en un determinado programa educativo.

El conjunto de estos modelos de docencia reconstruidos teóricamente, constituyen el trasfondo del trayecto formativo de grado del profesorado, conllevan visiones propias de la tarea docente y nutren de contenidos a las concepciones de los futuros profesores.

De cierta forma, la investigación realizada favoreció una aproximación a una realidad local no totalmente conocida y ofreció una visión general de la constitución del pensamiento pedagógico de los estudiantes de este profesorado.

\section{Aspectos metodológicos}

\section{Diseño}

Para la obtención de la información se emplearon dos procedimientos complementarios: el cuestionario semi-estructurado y los grupos focales. A su vez, la implementación de estos procedimientos permitió abordar el objeto de estudio desde 
el plano individual y el grupal. Además, el tratamiento de la información combinó análisis cuantitativo y cualitativo.

\section{Participantes}

Participaron veintidós estudiantes del profesorado en Ciencias de la Educación próximos a graduarse, quienes se encontraban cursando dos de las cuatro materias del último año de la carrera. Estos estudiantes del quinto y último nivel del profesorado han realizado ya las materias generales y específicas, y han tenido un primer contacto con las tareas y el rol docente a través del espacio curricular "Práctica de la Enseñanza y Residencia en Instituciones Educativas". También han accedido a la formación en investigación educativa a través de una asignatura y tres seminarios (Teoría y Métodos de la Investigación y los Seminarios de la Realidad Educativa, de Investigación Educativa I y II).

\section{Procedimientos}

Se aplicaron dos procedimientos de recolección de datos. El primer instrumento cuestionario semi-estructurado - se empleó con el fin de lograr una primera aproximación y caracterización del objeto de estudio, mientras que con el segundo Grupo Focal - se planteó discutir y ampliar estas características, para profundizar y esclarecer los significados de las concepciones de los estudiantes y su relación con los enfoques y tradiciones presentes en el campo de la formación docente.

\section{El cuestionario semi-estructurado}

Contenía preguntas de respuesta abierta y de respuestas pre-categorizadas en dos variantes, o bien debían jerarquizar según orden de preferencia distintas opciones presentadas; o bien tenían que señalar, según el caso, una o dos opciones consideradas importantes. Se buscó recabar información respecto a cómo los alumnos de Ciencias de la Educación, en la instancia final de su carrera, piensan e imaginan la actuación docente, qué características sobresalen, cuáles son los rasgos comunes y cuáles los diferenciados que emergen al anticipar y proyectar su futura práctica docente.

\section{Grupo Focal}

Se organizaron cuatro grupos focales de cinco miembros cada uno, buscando incluir estudiantes con distintos tiempos en el cursado de la carrera, provenientes de cohortes distintas, quienes - se suponía - poseen diversas opiniones y experiencias respecto de la temática en estudio. Esto fue importante porque contribuyó a generar y provocar en el interior de los grupos una atmósfera adecuada de discusión, lo cual permitió una mayor riqueza y provecho de los resultados. Esta técnica, que en los últimos tiempos viene ocupando un lugar destacado dentro del conjunto de las técnicas de relevamiento de la investigación cualitativa, puede definirse como una reunión de individuos seleccionados por el investigador para discutir y elaborar, desde la experiencia personal, una temática que es objeto de investigación. Tiene como propósito registrar cómo los participantes elaboran grupalmente su realidad y experiencia (Canales y Peinado, 1999)

En este sentido, se indagaron a través de este procedimiento aquellas cuestiones y dimensiones que se identificaron en el cuestionario con el sentido de profundizar su análisis.

especialmente se tomaron los asuntos que podrían resultar más polémicos y controvertidos: cómo aprenden a enseñar los futuros docentes; qué deberían saber y tendrían que hacer para generar una buena enseñanza; cómo es la relación teoría práctica en el proceso de enseñanza y aprendizaje; cuáles son sus creencias y 
concepciones sobre el modo de aprender de los alumnos; qué función debería cumplir la evaluación de los aprendizajes; qué es el docente: un intelectual, un crítico, un técnico o un práctico; con cuál se identifican y por qué; entre otras cuestiones.

Estos asuntos fueron tratados y discutidos abundantemente no sólo para ampliar las características de las modelizaciones de la actuación docente, también, fundamentalmente, para hallar y esclarecer las posibles relaciones de estos aspectos significativos con los postulados centrales de los modelos de docencia presentes en la formación del profesorado. En definitiva, se pudo examinar con mayor detalle el tipo de correspondencia de las anticipaciones y proyecciones realizadas sobre la actuación docente y los modelos de docencia mencionados.

\section{Presentación y análisis de resultados}

Los resultados que se exponen están organizados en dos categorías: las fuentes de aprendizaje docente y las características de la buena enseñanza y el buen aprendizaje. Con el objeto de realizar una aproximación más precisa a las concepciones de estos estudiantes, el análisis integra los datos obtenidos por las técnicas mencionadas. Los datos recabados mediante la aplicación del cuestionario se presentan en tablas, para un análisis cuantitativo de la información. Seguidamente, estos análisis se recuperan en el marco de las discusiones a que dieron lugar en los grupos focales. En este caso, las posiciones y argumentos defendidos en los grupos son objeto de un análisis cualitativo, enriquecido con citas ilustrativas. La interpretación se completa con la inclusión de conceptualizaciones de distintos autores.

\section{I- Las fuentes de aprendizaje docente.}

Para captar las fuentes de aprendizaje docente más valoradas el cuestionario incluyó una pregunta de respuesta pre-categorizada. Se presentaron una serie de enunciados que expresaban ideas afines a los distintos modelos de docencia. Se solicitó señalar la opción que se considerara más importante.

Tabla I: Fuentes de aprendizaje docente

\begin{tabular}{|c|c|}
\hline Aprender la profesión docente tiene que ver con: & $\begin{array}{c}\text { No de } \\
\text { menciones }\end{array}$ \\
\hline $\begin{array}{c}\text { - Incorporar y aplicar destrezas y competencias técnicas que derivan del } \\
\text { saber disciplinar }\end{array}$ & 6 \\
\hline - Incorporar los contenidos y la lógica interna de las disciplinas & - \\
\hline - Adquirir habilidades prácticas, se aprende a enseñar enseñando & 5 \\
\hline $\begin{array}{c}\text { - Estar conciente de las condiciones sociales e históricas en las que se } \\
\text { han formado nuestros modos de entender y valorar la práctica educativa }\end{array}$ & $\mathbf{1 1}$ \\
\hline Total & $\mathbf{2 2}$ \\
\hline
\end{tabular}


La opción más señalada como fuente de aprendizaje docente se encuadra en la perspectiva crítica. En cambio, escasos son los señalamientos para las alternativas pertenecientes a la tradición técnica y al enfoque práctico, ubicados en la primera y tercera fila respectivamente. Ningún estudiante mencionó la opción que hace referencia a la tradición academicista.

Justamente, la cuestión del lugar que ocupa el contenido disciplinar en la formación y el manejo sólido de la materia a enseñar, fue un eje importante y provocativo de discusión en los grupos focales. En este sentido, se registran en las producciones grupales ciertos acuerdos, en primer lugar, sobre la necesidad de una sólida formación disciplinar del docente en la asignatura que le corresponde enseñar, asimismo, reconocimiento de que no es suficiente para un buen ejercicio profesional. Algunas expresiones dan cuenta de la razón por la que no fue seleccionada la opción que enfatizaba el papel de los contenidos:

"....para mi eso está ya, sí o sí el docente posee una sólida formación teórica...",

"...es algo como dado, entonces se tratan otras cuestiones y no la formación disciplinar, porque se supone que el docente maneja sólidamente la materia que dictará...".

En estos dichos advertimos una clara conciencia de la importancia del dominio disciplinar para ser docente, no obstante, es planteado como una condición necesaria pero no suficiente, requiriendo de un dominio de conocimientos pedagógicodisciplinares como herramienta de análisis de la actuación docente,

“...la importancia del manejo del contenido reside no sólo para transmitir con confianza su materia sino también con el fin de analizar la realidad educativa en donde se concreta la enseñanza...".

En estas explicaciones los estudiantes no reducen la acción profesional del profesorado a los límites exclusivos del saber disciplinar. Aceptarlo equivaldría, sostienen Porlán y Rivero (1.998), a que el profesor centre su proceso de aprendizaje profesional en términos de conceptos abstractos y formales a adquirir obviando la complejidad de las situaciones de la práctica que debe enfrentar.

También, los estudiantes coincidieron al sostener que en su proceso formativo particular como docentes están atravesando y vivenciando una profunda modificación del modo tradicional de enseñar, en estas citas se sintetiza este planteamiento:

"creo que estamos viviendo un rechazo generalizado de una manera de enseñar que históricamente atravesó profundamente nuestra formación como profesores. Antes, quizás, se pensaba que al poseer sólo un cúmulo suficiente de contenidos se podía llevar adelante, sin sobresaltos, una clase..."

“...tiene que ver con el paradigma en el que estamos inmersos... no coincido con aquella postura que sostiene que lo más importante es que el profesor sepa solamente el contenido de su materia y eso es suficiente, se puede decir con razón que este profesor no se adecua a las nuevas exigencias, no es conocedor de las nuevas teorías del aprendizaje o de la enseñanza que actualmente se reconocen como superadoras de los modos tradicionales de ejercer la docencia...". 
En algunos grupos, los estudiantes consensuaron en que este rechazo generalizado del dominio exclusivo de los conocimientos a transmitir en el proceso de enseñanza, como fuente primordial para aprender a ser docente, produjo el efecto contrario, que el profesor carezca de solvencia disciplinar. Se transcribe un comentario en esta dirección:

“...nuestra carrera... ha dejado de lado la preparación del profesor que va a dar clases, los más perjudicado fueron los contenidos... se les restó importancia y se acrecentó la relevancia en otros asuntos... Me acuerdo cuando hace algunos años atrás, al mismo tiempo de iniciar la carrera se comenzó a implementar un nuevo plan de estudio para Ciencias de la Educación... se le achacaba al plan viejo su orientación academicista, es decir volcada exclusivamente hacia los contenidos disciplinares... ahora que me pongo a pensar finalizando la carrera, comparando ambos planes, en el nuevo se ampliaron las materias lo que significó mayor amplitud en la formación y al mismo tiempo, dispersión y vaciamiento de contenidos significativos... considero que una consecuencia no deseada es que se dejó de lado una cuestión central: la formación disciplinar... una despreocupación por el manejo experto de los contenidos de las materias a enseñar a favor de la atención de otras cuestiones...".

En esta misma línea otra estudiante expuso su punto de vista:

"...hay una ruptura, la formación que se ofrecía en el viejo plan fue severamente criticada y se propuso este plan como alternativo y con ello se corrió el eje de la formación de una que se centraba exclusivamente en la preparación de profesores para que den clases a otra que no sabemos muy bien lo que busca pero que dejó, comparativamente, esta exclusiva orientación, y al parecer esta arrojando, por lo menos en esta cohorte, egresados con poca preparación disciplinar...".

Por otra parte, en los intercambios discursivos, los estudiantes se mostraron renuentes respectos al conjunto de competencias técnicas que prescribe la acción profesional como fuente destacada de aprendizaje docente. Declaran que la intervención técnica en la enseñanza se asocia con la vertiente tecnocrática en educación.

Sintéticamente, aparece la fuerte creencia que ubica al dominio de contenidos disciplinares como condición necesaria aunque no suficiente para ser docente, y las competencias técnicas con un escaso reconocimiento valorativo. Se advierte que los grupos otorgaron un valor especialmente importante a los aprendizajes que se pueden generar desde la práctica concreta de enseñar, los estudiantes acordaron con la afirmación:

"El docente aprende a enseñar conforme enseña"

Se encontró una postura que adhiere más abiertamente a este enunciado y otra que se diferencia sensiblemente. Se registraron comentarios de este tipo:

"estoy convencido que se aprende a enseñar cuando efectivamente te toca dar clases..."; "...uno recién asume el rol de docente y dice que la práctica de enseñar será provechosa, en cuanto a los aprendizajes que pueden ser útiles, recién cuando comience a trabajar"; “...por más teoría que tengas encima me parece que la 
práctica de enseñar no se puede transmitir, no se aprende a enseñar siguiendo una receta, vos te haces haciendo...".

Estos estudiantes destacaron, además, que la práctica concreta de enseñanza puede ser fuente de aprendizaje si se la realiza antes, en los primeros años de la carrera,

"...en el caso de nuestro plan de estudio tenemos un espacio destinado a la práctica de la enseñanza, la viví como una asignatura más, no como algo trascendental, por momentos no encontré su sentido, el hecho mismo de ubicarla casi al final de la carrera como un espacio de aplicación más que de construcción de saberes, quizás, en alguna medida contribuyó a mi desinterés".

Criticaron la ubicación que en el plan de estudios se le otorga a la práctica de la enseñanza, puesto que la sitúan en el último tramo de la carrera, por tal motivo, dicen, se pierden y no se dan tanta importancia a los conocimientos y vivencias que pueden obtenerse solamente en situaciones concretas de enseñanza. Hablaron de la Residencia en instituciones educativas, dijeron que es muy corto el periodo de tiempo que se les brinda para que realicen sus prácticas. Se reproducen algunas opiniones:

“...es importante tener experiencia pero la que poseemos nosotros a partir de la práctica es insuficiente. Es muy poco el tiempo que nos dan para practicar si bien cuando vivimos esa experiencia fue muy importante, pero es como que algo le faltaba..."

“...se le da poco valor en la carrera porque la tenemos recién en el ultimo nivel del cursado, no se la tiene mucho en cuenta, no se le concede la importancia que se merece realmente...cuando empecé a tener confianza, a soltarme más, la experiencia llegó a su fin, solamente fueron cuatro clases...".

Un importante número de estudiantes entiende que en la carrera se da escasa valoración al aprendizaje que el futuro profesor pueda adquirir en la experiencia directa de enseñar. En este sentido, algunos manifestaron que el valor del aprendizaje experiencial radica no tanto en los saberes que se puedan adquirir sino, ante todo, en las actitudes y disposiciones que se pueden desarrollar en la experiencia misma de enseñar:

"La oportunidad durante la preparación inicial de tener la responsabilidad de llevar adelante una clase tutelado por un docente experto te permite afianzarte, ganar confianza...".

Abundantemente aparecieron en los grupos argumentos que hacían referencia al valor de la experiencia de enseñar en sí misma. También existió acuerdo en que la posibilidad de obtener alguna experiencia de enseñaza en el profesorado ayuda a quitar las dudas respecto a si la elección de ser docente es la correcta. Existe una convicción predominante en estos grupos, la fuente más importante de aprendizaje docente son los saberes que el profesor incorpora muchas veces espontáneamente en situación de enseñanza. Si bien estos futuros profesores no descartan la importancia de los otros componentes, privilegian los aprendizajes producto de la práctica concreta. 
Sin embargo, algunos se mostraron solo parcialmente de acuerdo, planteando que la práctica educativa se convierte en una experiencia fructífera de aprendizaje sólo si los futuros docentes son capaces de analizarla críticamente, con ayuda de un referente teórico más amplio. Al mismo tiempo, estos y otros estudiantes reconocieron que este procedimiento se encuentra condicionado y empobrecido por el tipo de material teórico que se les ofrece, al respecto expresaron:

“...esta idea de ubicar las prácticas como un lugar de puesta a prueba o espacio para reconstruir saberes está condicionado por el tipo de bibliografía que se trabaja, ¿qué nos dan? No leemos a los autores de las obras, las teorías son abordadas en sus aspectos generales, leemos reinterpretaciones, manuales, las ideas están empobrecidas, a veces sólo estudiamos fragmentos de capítulos".

Otras voces ubicaron el valor de la práctica como complemento de la teoría,

“....apoyando a los contenidos lo veo a la experiencia como un complemento... la experiencia y los contenidos van juntos, yo creo más en una combinación entre ambos".

En síntesis, aparece una fuerte tendencia que pone en primer plano la práctica como fuente de aprendizaje, resaltada más aún que las anteriores fuentes. Una proporción importante de los estudiantes confía en el conocimiento basado en la experiencia, por sí sólo; lo cual, en el pensamiento de Porlan y Rivero, tiene un fuerte componente conservador al ser el resultado de un largo proceso de adaptación a la cultura escolar y profesional dominante. En cambio, algunos parecen valorar los aprendizajes que se puedan obtener de la actividad concreta de enseñar, pero incluyendo la reflexión critica sobre la práctica como aspecto sustancial del proceso formativo del profesorado.

\section{II- Las características de la buena enseñanza y el buen aprendizaje.}

Los ítems del cuestionario preparados para captar el pensamiento de los estudiantes sobre la buena enseñaza y el buen aprendizaje se presentaron con opciones cerradas en forma de frases. Se solicitó marcar dos opciones en lugar de una, que luego fueron tratadas y ampliadas en las discusiones grupales.

\section{a.- La buena enseñanza}

Tabla Il: Características otorgadas la buena enseñanza

\begin{tabular}{|l|c|}
\hline La "buena enseñanza" acontece cuando el profesor: & $\begin{array}{c}\text { № total } \\
\text { de } \\
\text { menciones }\end{array}$ \\
\hline $\begin{array}{c}\text { - Expone de forma clara y ordenada los componentes fundamentales } \\
\text { de las disciplinas }\end{array}$ & $\mathbf{5}$ \\
\hline
\end{tabular}




\begin{tabular}{|l|c|}
\hline - Alcanza los objetivos que se ha fijado & - \\
\hline - Estimula la atención y el interés por el tema & 10 \\
\hline $\begin{array}{l}\text { - Organiza el ambiente para que el alumno pueda desenvolverse a su } \\
\text { propio ritmo, guiado por sus propios intereses }\end{array}$ & 6 \\
\hline $\begin{array}{l}\text { - Promueve aplicaciones prácticas para luego analizarlas y extraer } \\
\text { elementos más teóricos y de reflexión }\end{array}$ & 12 \\
\hline $\begin{array}{l}\text { - Asume la práctica escolar también como una práctica social, cultural } \\
\text { yolítica }\end{array}$ & 10 \\
\hline $\begin{array}{c}\text { - Programa y desarrolla su plan de enseñanza de manera metódica y } \\
\text { rigurosa }\end{array}$ & $\mathbf{1}$ \\
\hline TOTAL & 44 \\
\hline
\end{tabular}

Se advierte que las opciones más señaladas se corresponden con el modelo práctico reflexivo y con el crítico-emancipatorio respectivamente. En cambio, escasas menciones recibieron las opciones correspondientes a los modelos: práctico procesual y academicista. El modelo docente técnico-eficientista representado en dos opciones recibió una mención.

En los grupos focales existió cierto consenso en rechazar la idea de la buena clase asociada a la sola transmisión de contenidos, al respecto recabamos algunas opiniones:

"...esta idea de que el profesor imparte contenidos esta en crisis. Aunque determinados sectores de la sociedad aún siguen sosteniendo que la misión del docente es transmitir conocimientos ante todo, reclaman que esta tradición no se pierda..."; "... hay que romper con la idea de que el docente va a clase para impartir contenidos y listo...".

Se propuso a los distintos grupos que imaginen y luego verbalicen una buena situación de enseñanza. En principio, paradójicamente, le otorgaron gran importancia a la exposición del contenido de la asignatura, sin embargo, algunos aclararon que pensarían en actividades para desplegar la creatividad del alumno. En el reconocimiento explícito de la importancia de la transmisión de contenidos; agregaron, además, que al margen de esta forma general de abordar las clases, prefieren que éstas se desarrollen en un clima informal, en este sentido nos decía una estudiante:

"...que sea informal, no significa que deje la clase en manos del grupo, siempre soy yo quien dará el primer paso y para esto es fundamental un sólido manejo del contenido a transmitir...".

En los grupos, parte de sus integrantes han conceptualizado la enseñanza fundamentalmente como transmisión de contenidos, pero con ciertos matices que difícilmente se puedan encuadrar en este modo tradicional de enseñar, por ejemplo, se habló de la relación docente alumno: 
“...no es una relación de una sola dirección, el docente enseña y el alumno aprende, sino que se pueden sacar determinadas cuestiones que tanto a ellos como a nosotros nos puede resultar de gran utilidad...".

Igualmente hicieron alusión a la importancia de la disposición para aprender, en palabras de una estudiante:

“...es importante que el alumno este predispuesto para aprender, en ese brindar contenidos, espero que participe, hable, pregunte, no me imagino hablando sola, sino que espero que se me cuestione... generar una relación de ida y vuelta...".

Por último, un estudiante comparte el punto de vista del enseñar como transmisión pero, aclara, no como una imposición de contenidos:

“...que pregunten, que participen como una necesidad y no como una imposición... a pesar de todo creo que el contenido es fundamental, pero no el único factor que interviene... también considero que la excesiva preocupación en cómo se enseña condujo o a dejar en un segundo plano algo esencial y básico lo qué se va a enseñar, o sea los contenidos conceptuales".

Gros Salvat y Romañá Blay (2.004), consideran que los profesores notan que lo que mueve al alumno, en situación de enseñanza, no suele ser un desinteresado apego a la sabiduría. Quieren conocimientos corpóreos, datos humanos, ecuaciones si no vitales, sí vividas. La cuestión es hacer los contenidos un poco más cercanos al sentir de los alumnos, como decía un estudiante:

"...para lograr captar la atención de los alumnos y despertar su interés se debe hacer un contraste entre la teoría y la experiencia que uno puede tener respecto de lo que esta diciendo, es eso lo que va atrapando...".

En algunos grupos se resaltó que despertar el interés de los alumnos es una de las cuestiones más importantes que deberán enfrentar. Un estudiante puntualizó:

“...los grupos no son los mismos, no solamente hablo de los cambios que se producen año a año sino también del nivel educativo. Por ejemplo, no es lo mismo estar frente a alumnos del secundario que enfrentar a los que están en un terciario. En el secundario van por obligación y la indisciplina esta a la orden del día, en cambio en un terciario asisten porque eligen, por lo tanto será otro tipo de relación que se establecerá con ellos...".

Otros subrayaron la importancia de poseer una buena relación con los alumnos:

“... a mi me gustaría tener una buena relación con los alumnos... no sólo hay que preocuparse todo el tiempo por los contenidos y las formas de transmisión, sino que me parece importante dedicar tiempo a crear un clima ameno, de confianza, de dialogo como marco para los aprendizajes, buscaría la forma de llegar a los alumnos y no pasaría mucho tiempo explicando conceptos". 
Inclusive, mencionaron que una buena enseñanza dependerá fundamentalmente del espíritu de los profesores, de sus ganas por enseñar, por innovar, y desarrollar distintas estrategias para conseguir que los alumnos aprendan.

Adicionalmente, en los grupos surgieron comentarios sobre la práctica de enseñanza como una práctica social y política, existe cierta conciencia en algunos estudiantes en presentar la enseñanza no sólo como un asunto educativo sino también como un hecho social y político. Al respecto lo dicho por un alumno ilustra esta postura:

“...no se puede pensar en la escuela como un espacio cerrado, impermeable a lo que sucede en el contexto", "...en nuestro trabajo enfrentamos situaciones en donde debemos tomar decisiones de carácter éticas".

En este sentido, otra alumna mencionó:

“...los saberes que se transmiten y la forma en que se lo hace no son neutros, ni desinteresados. Pareciera que el conocimiento que se transmite en la escuela es puramente objetivo y desinteresado y lo que está contaminado es lo que rodea a ella, lo que está afuera, pero sostengo que es muy difícil no mezclar y aislar el saber de cuestiones ideológicas y de intereses particulares".

Un estudiante agregó:

“...la práctica escolar forma parte de la sociedad... se inculcan valores, normas, se establecen costumbres, la escuela es una institución de socialización indudablemente... es que la práctica escolar es en sí social, cultural y política no puede abstenerse de esas otras características".

En torno a este aspecto se generó polémica, una postura que pregona una separación entre la escuela y el contexto que la rodea que sólo la afecta desde el exterior; en el discurso de los partidarios de esta postura se enfatizó frecuentemente la palabra filtro:

“...partamos de la base que la práctica escolar se encuentra ubicada en un contexto característico de una época histórica. $Y$ eso indudablemente va a filtrar..."; “...es imposible negar el acceso -presencia- de estos factores al aula... la determina, la caracteriza..."; "...filtrar hace referencia a la entrada innegable y hasta imposible de parar si uno quiere negar el contexto. Por ejemplo, el chico viene de afuera y es portador de un montón de influencias...".

La otra posición, también concibiendo la práctica escolar como social y política se diferencia sensiblemente, considerando que lo social es inherente a la práctica educativa,

"...ya se advirtió hace mucho tiempo que la escuela no es una isla, las aulas tampoco... existe una intima interconexión entre todos estos aspectos, no sólo porque repercuten en la escuela sino que nacen con ella."; "...la palabra filtro da la sensación de que estamos hablando de algo externo, ajeno a la institución educativa, se esta metiendo en ella se esta colando, al estar de acuerdo con esto se esta negando la naturaleza social y política de la educación.”; “...están diciendo 
que la escuela es algo puro en donde todos los males de la sociedad por algún huequito están entrando... la escuela es parte de la sociedad".

Para algunos la práctica escolar, de la que forma parte el enseñar, es entendida como una práctica social por el hecho mismo de ser producto de la acción humana.

En síntesis, existe una postura prevaleciente en los grupos de estudiantes futuros profesores, se considera que el docente para lograr una buena enseñanza tiene que plantearse la transmisión del contenido disciplinar de un modo flexible, atendiendo a las necesidades formativas de los alumnos, creando un clima cálido de clase, promoviendo diversas actividades que estimulen el aprendizajes escolar y entablando una relación si bien asimétrica no autoritaria con los alumnos. En menor medida, surgieron planteamientos que asocian el estilo del profesor, su carisma como promotoras de una buena enseñanza. Otros, plantearon que las características de la buena enseñanza variará según el nivel en donde ésta se sitúe. Algunos estudiantes finalmente plantearon que una buena enseñanza se alcanza cuando existe una práctica educativa comprometida con la emancipación política de sus actores.

b.- El buen aprendizaje

Tabla III: Características otorgadas al buen aprendizaje

\begin{tabular}{|c|c|}
\hline El "buen aprendizaje” ocurre cuando los alumnos: & $\begin{array}{c}\text { № total } \\
\text { de } \\
\text { menciones }\end{array}$ \\
\hline - Relacionan los conocimientos que están adquiriendo & $\mathbf{1 3}$ \\
\hline - Comprenden los significados de lo que están estudiando & $\mathbf{1 2}$ \\
\hline $\begin{array}{c}\text { - Descubren de manera personal y autónoma lo que se ha de } \\
\text { aprender }\end{array}$ & $\mathbf{3}$ \\
\hline $\begin{array}{c}\text { - Fijan y recuperan conocimientos respetando la fidelidad de los } \\
\text { contenidos disciplinares } \\
\text { - Elaboran un proyecto, resuelven un problema o realizan una }\end{array}$ & $\mathbf{2}$ \\
\hline investigación & $\mathbf{1 0}$ \\
\hline - Modifican su conducta conforme logran objetivos específicos & $\mathbf{4 4}$ \\
\hline
\end{tabular}

Las opciones con mayor cantidad de señalamientos se las pueden relacionar con modelos de docencia actuales, más precisamente a los enfoques de docencia práctico-reflexivo y el crítico-emancipatorio. Las opciones con menor número de 
señalamientos refieren al modelo práctico procesual, al modelo academicista, y al modelo tecnocrático.

En términos generales, los grupos focales acordaron que los buenos aprendizajes pueden suceder cuando el docente es capaz de percibir las necesidades de aprendizaje de los alumnos y organizar el contenido en función de los mismos. Además, surgieron planteamientos orientados a las condiciones a priori que se deben establecer en cuanto a las relaciones entre docente - alumno en clase, se manifestó la importancia de que el docente creé un ambiente calido y agradable en la clase, y paralelamente el alumno muestre un especial interés o motivación para emprender el proceso de aprendizaje, debe tener sentido para él apropiarse significativamente del conocimiento. Otro grupo focal discutió y acordó que los buenos aprendizajes son productos de la posibilidad de transferir lo adquirir en clase por parte del alumno a situaciones concretas y nuevas. Finalmente, se planteó la necesidad de relacionar conocimientos nuevos con los que ya dispone el alumno sobre una determinada temática.

Respecto a la primera postura mencionada, algunos estudiantes consideraron que los alumnos logran buenos aprendizajes en gran medido porque el docente es capaz de captar sus intereses, aprovechar sus experiencias, compatibilizar sus necesidades naturales de aprendizaje con el contenido a transmitir, en palabras de estos futuros profesores:

"...debemos agotar todas las posibilidades de adecuar los contenidos a las necesidades de aprendizaje de los alumnos".

“...hay que aprovechar las experiencias de los alumnos y hacer que el aprendizaje siempre sea significativos..."

“...el contenido, como verán, no es mi preocupación central, prefiero abordar pocos contenidos pero profundizarlos"

"...no creo que haya que ir a exponer todos los temas... ...requiere que el profesor sepa adecuar los contenidos a las necesidades de aprendizaje de sus alumnos"

Además, surgieron en los grupos otras cuestiones, que se detallan a continuación:

Predominantemente en algunos grupos sostienen que el buen aprendizaje ocurre fundamentalmente cuando el profesor crea un ambiente cálido y agradable en la clase y, conjuntamente, cuando el alumno está suficientemente motivado para aprender. Al respecto se manifestó:

"..un conjunto de todo, de que el profesor brinde o cree un ambiente, es lo que decíamos recién, algo ameno, algo creativo, la predisposición del alumno, las ganas que le pueda llegar a poner..."

Otros participantes argumentaron que un buen aprendizaje tiene estrecho vínculo con transferir lo aprendido a otros ámbitos, un ejemplo de este planteamiento se encuentra en las siguientes citas: 
“...que el alumno pueda aplicar, que pueda trasladar a otros ámbitos de la vida; no que aprenda tales o determinados conceptos sino que se pueda hacer viable en otras situaciones de la vida..."

"El buen aprendizaje ocurre cuando los alumnos pueden aplicar lo que se le ha brindado desde el espacio de enseñanza hacia otras realidades de la vida cotidiana. Me parece que ahí seria significativo, de qué le sirve al alumno saber toda la teoría sino la puede aplicar a la realidad..."

"...considero de importancia que el alumno pueda conseguir esa conexión con la realidad, que pueda articular la teoría con la práctica..."

Aún otros estudiantes argumentaron que el "buen aprendizaje" acontece cuando se relaciona el conocimiento nuevo que proviene de las disciplinas objeto de estudio y los saberes previos que posee el alumno. Al respecto informan estos estudiantes:

"Ocurre cuando pueden descubrir la relación entre los conocimientos teóricos que brinda el docente y aquel conocimiento que proviene de la experiencia que posee el alumno..."

"...relacionar estos saberes es importante, articularlos, otorgarles sentido para que después no desaparezcan y no te sirvan para nada sólo para resolver con éxito un examen..."

"...para que suceda el buen aprendizaje, primero es importante que el alumno encuentre el significado de lo que está estudiando... que llegue a comprender algo que le esté ocurriendo teniendo en cuenta esa teoría..."

Estos acuerdos en algunos casos evidenciaron ciertas polémicas, en las siguientes citas se logran apreciar algunas de ellas:

"En mi opinión y por más que esto suene poco agradable, no creo que el profesor tenga que pararse frente del aula y preguntar a los alumnos que les interesaría aprender..."

"...los alumnos, hoy día, son apáticos, desinteresados, movidos por motivos que no se prestan para que el docente haga un trabajo educativo con ello..."

“...depende del grupo clase ante el cual estaremos parados, aunque siempre considero que se debe captar el interés de los alumnos presentándoles cosas nuevas, no más de lo mismo..."

Finalmente, se reflexionó sobre la enseñanza y el aprendizaje como procesos integrados, pensando en la "buena enseñanza" como productora de condiciones para que ocurran "buenos aprendizajes", aunque en general la mayoría entiende que la enseñanza y aprendizaje son procesos diferentes:

"Son procesos diferentes que no necesariamente van juntos... puede que ocurra una buena enseñanza sin que se haya producido un verdadero aprendizaje, la relación no es lineal... nunca se garantiza el cien por cien de éxito por más buena que sea la enseñanza. Como decíamos hoy influyen factores de diversa índole... aunque tampoco los aprendizajes que pueden realizar los alumnos no terminan en las escuelas... ...se diferencian porque son producto de una enseñanza intencional..." 
Asimismo, destacaron los futuros profesores que para conseguir que los alumnos aprendan, primero dependen de las ganas que tengan de hacerlo y después con que el profesor genere un ambiente cálido, cordial y de confianza con sus alumnos. En este mismo sentido una estudiante expuso su punto de vista:

“...habiendo una enseñanza para que ocurra un aprendizaje, lo ideal seria que el alumno se preste a ese juego, a esa negociación en el aula, que el alumno este predispuesto, eso me parece fundamental, junto con que el profesor cree ciertas condiciones, un buen ambiente, algo ameno..."

Reconocieron que el alumno aprende todo el tiempo, espontáneamente. Sin embargo, la enseñanza aparece como importante si se pretende que los alumnos se apropien de conocimientos más elaborados y específicos, en este sentido manifestaron dos estudiantes:

“...es necesario la enseñanza si buscamos que los alumnos se apropien de conocimientos más elaborados y específicos se hace necesario una intervención sistemática, esto se da en el marco de una relación asimétrica, en donde el docente posee el conocimientos sistemático y lo transmite, y el alumno posee un saber menos elaborado y desorganizado..."

“...se necesita del docente que será quien seleccione y organice el conocimiento para luego transmitirlo...pero los dos en ese proceso van a aprender algo..."

En síntesis, surgieron diversos planteamientos en los grupos, no existió una postura dominante respecto a las características atribuibles al buen aprendizaje; más bien, surgieron diferentes posicionamientos. Para algunos los buenos aprendizajes logran los alumnos cuando son capaces de aplicar o transferir lo aprendido a situaciones nuevas. Otros, prefirieron colocar la cuestión en la capacidad del alumno para relacionar conocimientos nuevos con los conocimientos que ya posee. En cambio, algunos estudiantes sostuvieron la importancia de aspectos motivacionales en los buenos aprendizajes. Y finalmente, también agregaron como aspecto preponderante en el logro de buenos aprendizajes, la predisposición del profesor para generar un clima cálido y agradable de trabajo en clase.

\section{Conclusiones}

El análisis de los datos obtenidos a partir del cuestionario mostró que las concepciones de los futuros profesores, se estructuran mediante una relación de correspondencia de tipo coherente con dos modelos de docencia, y, además, una marcada correspondencia de polaridad entre modelos.

La fuente de aprendizaje docente más valorada remite exclusivamente a la perspectiva crítica. Coherentemente, las imágenes de la "buena enseñanza" y el "buen aprendizaje" contienen elementos predominantes que comparten el enfoque práctico reflexivo y el crítico. En ambos casos, y aquí surge la relación de polaridad, las tradiciones academicista y técnico-eficientista no tienen presencia en las valoraciones de estos estudiantes. 
Distintamente, en el análisis de las producciones grupales, entrevemos cierta dilución y de algún modo volatilización de la correspondencia configurada, nos sitúa en una conjunción más profunda que podemos caracterizar como concepciones constituidas por una mixtura de perspectivas de diferentes orígenes.

La interpretación de los resultados, más allá de la aparente inconsistencia, remite a la íntima relación entre conocimiento especializado, creencias y concepciones, relación que viene ocupando un lugar destacado en los estudios sobre el conocimiento profesional del docente (Molpeceres et al., 2004; Pozo, 2006; Latorre Medina y Blanco Encomienda, 2007; Serrano Sánchez, 2010).

Retomando la distinción que realiza Pozo (2009), entre conocimiento especializado o científico y concepciones implícitas, se concluye que las respuestas obtenidas en el cuestionario están próximas al reconocimiento conciente de conocimiento especializado, en este caso correspondientes a los modelos teóricos de docencia; en cambio, los grupos focales facilitaron la aproximación a las concepciones. Se trata de posibilidades complementarias pero diferenciadas de los procedimientos metodológicos. El cuestionario como instrumento más estructurado se mostró adecuado para captar los saberes sistematizados en el proceso de formación. Los grupos focales, en el fluir espontáneo de los intercambios, permitieron la emergencia de saberes conformados como versiones parciales asumidas como propias a partir de conocimiento explicito o repertorio de modelos culturales disponibles sobre el mismo fenómeno.

En lo que sigue se reseña lo que se entiende configuran concepciones implícitas referidas a las fuentes de aprendizaje docente, a la buena enseñanza y al buen aprendizaje.

En primer lugar, surge que los estudiantes comparten la creencia de que la práctica de enseñanza es la fuente más importante para los aprendizajes docentes, es decir, existe la convicción común que los conocimientos que obtiene el docente vivenciando situaciones de enseñanza en las escuelas le proporciona un repertorio de conocimientos, disposiciones y actitudes favorables a su desempeño profesional. Consistentemente, destacan el valor del aprendizaje producto de la experiencia para la formación docente, en este sentido plantearon como necesidad ubicar la asignatura práctica de la enseñanza desde el comienzo de la carrera del profesorado.

Otra fuerte convicción compartida, remite al reconocimiento de la necesidad de una sólida formación disciplinar del docente en cuanto al qué y al cómo enseñar, aunque matizada por la certeza de que para un buen ejercicio profesional esto no sería suficiente. Un dato llamativo, surgido en los intercambios grupales, es el enfático rechazo de las intervenciones técnicas en la enseñanza que prescriben la acción docente, entendidas como paquetes de instrucciones, lo cual supone un fuerte distanciamiento del enfoque técnico y es coherente con las posiciones adoptadas. Lo consideramos llamativo porque conlleva connotaciones negativas exclusivamente, sin matizaciones.

Finalmente, cabría preguntarse por qué en los grupos no se expresó con cierta claridad una postura que aluda a la perspectiva crítica. Posiblemente se deba a que dicha teoría, como lo afirman Molpeceres y sus colegas, no ha encontrado aún en el sistema educativo una encarnación institucional ni una traducción normativa que permitan concebirla como una alternativa reconocible y viable desde un punto de vista práctico.

En segundo lugar, se advierte que la mayor parte de los estudiantes al imaginar una buena situación de enseñanza, colocó la transmisión del contenido disciplinar en 
un lugar destacado. Algunos acordaron en cuanto a complementarla con el desarrollo de actividades de aprendizajes que desplieguen la creatividad de los alumnos. Otros, plantearon que el docente, aparte de impartir conocimiento, deberá crear un clima cordial, ameno, cálido en la clase. También, surgió que la transmisión no deberá ser una imposición arbitraria, la relación se basará en una constante retroalimentación. En definitiva, la imagen de la buena enseñanza se estructura a partir de la transmisión de contenidos de un modo flexible, ya sea atendiendo al clima de clase, a las actividades de aprendizaje, o a la relación docente-alumno. Complementariamente, se pone en un plano destacado el impulso del profesor por innovar, probar distintas estrategias, mostrar ganas de enseñar, considerando que esto posee un efecto contagio para la clase. En algunos grupos, se expresó la afirmación, para llevar adelante una buena enseñanza primero debemos tener presente el nivel del sistema educativo, ya que según cuál sea tendremos ciertas regularidades que atender. Apareció la convicción de que tendrán que desarrollar estrategias de control y disciplina para el nivel medio, en cambio para el nivel superior tendrían que poner más cuidado en la manera de transmitir el conocimiento. Por último, existió polémica en algunos grupos respecto a cómo se venía imaginando la buena enseñanza, plantearon que no hay que considerarla como un hecho aislado de asuntos sociales y políticos.

En tercer y último lugar, en las producciones grupales referidas al logro por parte de los alumnos de buenos aprendizajes, se pudo diferenciar cuatros posturas que no son excluyentes sino todo lo contrario se las pueden integrar. Cada uno de estos planteos ubica de un modo prevaleciente un determinado aspecto, parte de los grupos consideran importante que el alumno pueda transferir conocimientos, para otros, que el alumno establezca a nivel cognitivo relaciones significativas entre conocimientos. Distintamente, algunos estudiantes colocaron en un lugar destacado la motivación en cuanto a las ganas y disposición de los alumnos para aprender. También, plantearon la importancia de que el profesor incida en el ambiente áulico para generar un clima adecuado para el aprendizaje.

En definitiva, los futuros profesores de Ciencias de la Educación, en la instancia final de su trayecto formativo de grado, son especialmente conocedores de diferentes teorías o modelos de docencia. A diferencia de otros profesorados, pueden entender las premisas de cada una de ellas, pero sólo comparten y adhieren algunos de sus presupuestos. En este sentido, construyen y asumen concepciones y creencias que podrán orientar su iniciación en la docencia, más allá de la mayor o menor coherencia de los elementos que las componen. Estas concepciones se activan y afloran toda vez que existe demanda puntual, en el caso de estos estudiantes posicionados como futuros profesores valorando y proyectándose respecto a cuestiones y dimensiones relevantes de la actuación docente.

\section{Bibliografía}

Angulo Calzadilla, G. (2012) "Las Concepciones sobre el docente o diferentes maneras de concebir el ejercicio de la docencia". En Rev. de Investigación $\mathrm{N}^{\circ}$ 75 Vol. 36. Pp. 11 - 32. <dialnet.noreply@bib.unirioja.es> [consulta oct., 2012]

Apple, M. (1986) Ideologia y currículum. Madrid, Akal.

Canales, P. y Peinado, A. (1999) "Grupos de Discusión". En DELGADO, J. y GUTIÉRREZ, J. (coords.) Métodos y Técnicas Cualitativas de Investigación en Ciencias Sociales. España. Síntesis de Psicología.

Carr, W. y Kemmis, S. (1988) Teoría crítica de la enseñanza. La investigación-acción en la formación del profesorado. Barcelona, Martínez Roca. 
Contreras Domingo, J. (1996) "Teoría y Práctica docente". Revista Cuadernos de Pedagogía, № 53. España.

Clark, C. M. y Peterson, P. L. (1986). "Procesos de pensamiento de los docentes". En WITTROCK, M. (Coord.) La investigación en la enseñanza, III. Profesores y alumnos. Madrid, Piadós.

Cordova, D. (2006) El pensamiento pedagógico de los estudiantes de educación.: Una investigación en los Estudios Universitarios Supervisados de la Universidad Central de Venezuela. Rev. Ped. vol.27, n.79 pp. 231-269. <http://www.scielo.org.ve/scielo.php> [consulta nov., 2011] ISSN 0798-9792.

Davini, M. C. (1995) La formación docente en cuestión: política y pedagogía. Bs. As., Paidós.

Dodera, G., Burroni, E., Lázaro, P. y Piacentini, B. (2008). "Concepciones y creencias de profesores sobre enseñanza y aprendizaje de la matemática". En Revista Premisa de la Sociedad Argentina de Educación Matemática. Año 10 №. 39, pp. 5-26. <www.soarem.org.ar/Documentos/39\%20Dodera.pd> [consulta agosto, 2012]

Diker, G. y Terigi, F. (1997) La formación de maestros y profesores: hoja de ruta. Bs. As., Piadós.

Figueroa, N. y Páez, H. (2009) Pensamiento didáctico del docente universitario. Una perspectiva desde la reflexión sobre su práctica pedagógica. En Rev. Fundamentos en humanidades. Universidad Nacional de San Luis - Argentina. Año IX, Número II. $\quad$ Pp. $\quad 111 \quad$ - 113. $<$ http://redalyc.uaemex.mx/pdf/184/18411970006.pdf> [consulta: Julio, 2012]

Freire, P. (1990) La naturaleza política de la educación. Cultura, poder y liberación. Barcelona, Paidós.

Gimeno Sacristán, J. (1983) La enseñanza. Su teoría y su práctica. Madrid. Akal.

Giroux, H. (1990) Los profesores como intelectuales transformativos. Barcelona, Paidós.

Gros Salvat, B. y Romañá Blay, T. (2004) Ser profesor. Palabras sobre la docencia universitaria. Barcelona, Octaedro.

Latorre Medina, M. J. y Blanco Encomienda, F. (2007) "Algunos conceptos clave en torno a las creencias de los docentes en formación". Revista Docencia e Investigación. Núm. 17. Escuela Universitaria de Magisterio de Toledo. España.

Marcelo, C. (1987). El pensamiento del profesor. Barcelona, CEAC.

Molpeceres, M.; Chulvi, B.; Bernad, J. (2004) "Concepciones sobre la enseñanza y prácticas docentes en un sistema educativo en transformación: un análisis en los PGS". Centro Interamericano de investigación y documentación sobre formación docente. Pp. 141-196. España.

Pérez Gómez, A. (1992) "La función y formación del profesor en la enseñanza para la comprensión". En GIMENO SACRISTÁN, J. y PÉREZ GÓMEZ, A. (coords.) Comprender y transformar la escuela. Madrid, Morata.

Porlán, R. y Rivero, A. (1998) El conocimiento de los profesores. España, Díada.

Pozo, J. (2001). Humana Mente. El mundo, la conciencia y la carne. Madrid, Morata. 
Pozo, J. (2003) Adquisición de conocimiento: cuando la carne se hace verbo. Madrid, Morata.

Pozo, J.; Scheuer, N.; Mateos, M. y Pérez Echeverría (2006) "Las teorías implícitas sobre el aprendizaje y la enseñanza”. En POZO, J. (Coord.) Nuevas formas de pensar la enseñanza y el aprendizaje. Barcelona, GRAO.

Pozo, J (2009) "Adquirir una concepción compleja del conocimiento: creencias epistemologicas y concepciones de aprendizaje". En POZO, J. y PUY PEREZ ECHEVERRIA, M. (Coords.) Psicología del aprendizaje universitario: La formación en competencias. Madrid, Morata.

Rodrigo, M. J., Rodríguez, A. y Marrero, J. (1993): Las teorías implícitas. Una aproximación al conocimiento cotidiano. Madrid, Visor.

Rodríguez, A. (1995) Un enfoque interdisciplinar en la formación de los maestros. Madrid, Nancea.

Schon (1992) La formación de profesionales reflexivos. Hacia un nuevo diseño de la enseñanza y el aprendizaje en la profesión. Barcelona, Paidós.

Serrano Sánchez, R. C. (2010): "Pensamientos del profesor: Un acercamiento a las creencias y concepciones sobre el proceso de enseñanza-aprendizaje en la Educación Superior". Revista de Educación, Num. 352. Universidad de Málaga, España.

Shavelson, R. y Stern, P. (1989) "Investigación sobre el pensamiento pedagógico del profesor, sus juicios, decisiones y conductas". En GIMENO, J. y PEREZ, A. (comp.) La enseñanza: su teoría y su práctica. Madrid, Akal.

Shulman, L. (1989) "Paradigmas y programas de investigación en el estudio de la enseñanza: una perspectiva contemporánea". En WITTROCK, M. (Coord.) La investigación de la enseñanza, I. Enfoques, teorías y métodos. Barcelona, Piadós.

Vaillant, D. (2005). Formación de docentes en América Latina. Re-inventando el modelo tradicional. Barcelona, Octaedro.

Yinger, R. (1986) "Investigación sobre el conocimiento y pensamiento de los profesores: hacia una concepción de la actividad profesional". En VILLAR, L. (coord.) Pensamiento de los profesores y toma de decisiones. Sevilla, Universidad de Sevilla. 